\title{
Age Differences in \\ Cognitive Personal Networks
}

\author{
Christopher Steven Marcum, PhD \\ Corresponding author \\ National Institutes of Health, \\ 31 Center Drive \\ Bethesda, Maryland 20894 \\ chris.marcum@nih.gov \\ Jielu Lin, PhD \\ University of Northern Arizona \\ Flagstaff, AZ \\ Jielu.Lin@nau.edu \\ Laura M. Koehly, PhD \\ National Institutes of Health \\ 31 Center Drive \\ Bethesda, Maryland 20894 \\ koehlyl@mail.nih.gov
}

Acknowledgements: We wish to thank the fellows of the Social Network Methods Section of the National Human Genome Research Institute, especially Dr. Jeffrey Rewley, for supporting the administration of the data used in this study.

COI: The authors have no conflicts of interest to report.

Author Contributions: CSM designed the study, oversaw the data administration, conducted the analysis, and wrote the paper. JL assisted with analysis and wrote the paper. LMK designed the study and assisted with writing and revising the paper. 


\section{Funding}

This work was supported by the Intramural Research Program of the National Institutes of Health (ZIA HG200397). 
Age Differences in Cognitive Personal Networks

\begin{abstract}
Background and Objectives

Previous research has found a negative association between network size and age, suggesting that people experience greater isolation from their personal networks with advancing age. In this paper, we evaluate age differences in how individuals perceive their social worlds to be structured, rather than focusing solely on network size.

Research Design \& Methods

A nationally represented sample of respondents $(n=1,824)$ reported on their own ties to their close personal network members (i.e., ego-alter ties) as well as their perceptions of the acquaintanceship between those members (i.e., alter-alter ties). We used social network analysis to assess how the structure of these relationships vary by respondent age.

Results

There is a strong pattern of age-homophily with some inter-generational contact for both ego-toalter and alter-to-alter ties. Egos perceive less age-heterophily among their alters than they perceive in their own ties. Net of the results for age-mixing, we find a positive association between ego age and personal network size and a negative association between average alter age and personal network size. Finally, we find that as alters' ages increase, their expected degrees as perceived by ego decreases regardless of ego's own age.

Discussion \& Implication

Our results suggest that our social worlds shift in terms of size and structure across the life course. While contemporary close personal networks may grow slightly with age, our perceptions of older people having fewer network ties remains. We discuss these results in the context of recent findings that suggest aging uniformly insulates individuals from social contact from both structural and symbolic perspectives. Specifically, the findings here challenge the notion that network size declines with age suggesting that this result may be the product of perceptions and not reality.
\end{abstract}

\title{
Background and Objectives
}

Recent demographic projections suggest that, in the United States, individuals may be more likely to age alone (Margolis \& Verdery, 2017; Verdery \& Margolis, 2017) and as a result, be subject to the detrimental effects of social isolation (Cornwell \& Waite, 2009). This phenomenon has been attributed to an increasing number of older adults who are unmarried, childless, and siblingless, which translates into additional constraints on the extent to which network size and composition can change (see, Carr \& Moorman, 2011). On the other hand, there is also considerable evidence that older adults in fact have comparably-sized or even larger networks than their younger counterparts through various forms of social participation (van Tilburg, 1998; Ajrouch, Antonucci, \& Webster, 2014; Marcum, 2013; Cornwell \& Laumann, 2018).

Conceptual developments in gerontology, particularly the integration of social networks and the linked lives' perspective (see Alwin, 2018 and Cornwell, Marcum, \& Silverstein, 2015), suggests that social networks change, not as a simple matter of losing or gaining ties; rather, they change 
in the context of various life course processes, events and transitions (Suitor et al., 1997; Feld et al. 2007). How these changes manifest requires a direct examination of age-based patterns in not only network size, but also heterogeneity in network structure. This paper looks at the role of age in social networks in the context of the new demographic reality of people living longer, healthier lives. Here, we consider age differences in key features of social networks that is, 1) the age composition of network members; 2) heterogeneity in network structure; and 3) differences in age-based patterns between one's own connections (i.e., ego's network size) and the perceptions of connections among others in close personal networks (i.e., perceived alter degree).

We accomplish this goal by focusing our lens on the networks that are most likely to be affected by the demographic processes underlying the phenomenon of aging alone: close personal networks, that is, the relationships individuals have with their family members, close friends, and important others. We consider two distinct ways through which social forces influence these patterns in close personal networks: structural and symbolic.

From a structural lens, having network members immediately nearby for support is particularly important for health and well-being (Mok and Wellman, 2007; Smith et al., 2015). While this perspective may be troubling given reported reductions in available social resources as one ages, an expanded view of the role of personal networks and health may ameliorate such concerns. For example, despite the fact that families will become, on average, smaller within a given generation, there is some evidence of a reemergence of the importance of multigenerational families, providing a context where there are more opportunities for personal network ties to span young and old across two, three, or even four generations (Marcum \& Koehly, 2015; Baker, Silverstein, \& Putney, 2010; Bengtson, 2001; Putney \& Bengtson, 2003). Social networks of older adults have recently been found to be sources of rich, rewarding social interaction even if overall personal network size declines with age (Cornwell, Laumann, \& Schumm, 2008). Additionally, the last two decades have been characterized by continued compression of mortality and morbidity, which avails individuals of healthier, longer-living, peers to engage with socially (Crimmins, \& Beltrán-Sánchez, 2011; Fries, 2002). And while mortality has long been seen to prune network ties, especially among older people, recent evidence by Cornwell \& Laumann (2018) suggests that deaths in one's network may facilitate future network growth.

These demographic trends have greatly shaped intra- and inter-generational structure, while older siblings and friends age together (Field \& Minkler, 1988; Rook, \& Ituarte, 1999; Silverstein, \& Giarrusso, 2010; White, 2001), and more possibility for connections spanning multiple generations (Bengtson, 2001; Putney \& Bengtson, 2003). As a result of the constant interplay between individual agency and structural constraints, we may observe new patterns in close personal networks characterized by a combination of both age homophily (close friends, siblings, cousins) and age heterophily (inter-generational relations). Making these observations requires attention to the problem of heterogeneity in age-based differences in network size and age composition, driven by complex social mechanisms. We expect there to be evidence of strong age-homophily as the age-grading of institutions, biology, and families tend to draw 
similarly aged people to connect socially (McPherson et al., 2001). Moreover, while some ageheterophily may be present overall, given recent trends, we expect this heterophily to fall along the lines of clear intergenerational patterning, with age-mixing concentrated roughly between 25-year age gaps (about the width of generation).

Second, while a key conceptual perspective, age as a symbolic construct is seldom taken into account in previous literature on networks over the life course. Social structure organizes the life course largely through age-grading, which can affect what is perceived as normative human behavior (Kohli et al., 2009; Kohli, 2000). Therefore, individuals' perceptions of the age pattern of others' social ties may be very different from objectively observed reality and from perceptions of one's own network. Such perceptions may matter for the perpetuation of stereotypes of aging leading to smaller social networks; thus, symbolic representations of aging as a marginalization process become embodied in the collective conscious (Sherman et al., 1985; Ward, 1984). Despite being plausible, this hypothesis has not been explicitly tested, largely due to the lack of network data that allows such inquiries to be tested. Ideally, to evaluate such hypotheses, one would need to consider not only to whom older adults' are directly connected (i.e., their personal networks), but also their personal network members' direct connections. A second-order tier of data, however, might include personal perceptions of older adults' own networks along with personal perceptions of how members of their personal networks are connected to each other (Krackhardt, 1987).

The majority of research in investigating how networks are patterned over the lifecourse does not take such an approach. However, previous work employing a cognitive social structure approach has shown that in organizational settings there are biases in how individuals cognitively organize the social structure within a given group (Krackhardt, 1987). One example suggests that third-party observers and those involved tend to perceive reciprocal exchange in advice, even when the observed network data do not support reciprocal advice exchange among organizational members (Koehly \& Pattison, 2005). People perceive more clustering in friendship networks than actually exists and greater centrality and brokerage for those people perceived to be popular than those who are objectively popular (Kilduff, Crossland, Tsai, \& Krackhardt, 2008). As well, those with high betweenness centrality - that is, network members in the middle of the network rather than the periphery - are more accurate in representing the unfolding advice structure (Krackhardt, 1987). Finally, there is a consistent pattern of bias with organizational members perceiving that they have more connections to others (i.e., outdegree) than others perceive them to have (Kumbasar, Romney, \& Batchelder, 1994). Such perceptual biases represent a cognitive schema in how we organize our social world, reflecting symbolic interactions that may not represent reality.

Survey methods in studies of older adults' social networks have primarily focused on either egocentered aspects of personal networks or on focal dyads. Such approaches are adept at informing us about the immediate relational context, that is, individuals' perceptions of their relationships with network members, or perceptions of relationships between pairs of connected individuals recruited into a study together. Much less research has extended the line of research to capture socio-centric phenomena, such as age differences in how individuals perceive the 
network structure among the members of their personal networks. There are valuable exceptions, such as the work by Schafer (2014) and by Ashida (Ashida \& Heaney, 2008; Koehly et al. 2015; Ashida et al. 2018; Marcum et al., 2018), but these studies tend to rely on relatively small networks conducted in specific settings (such as nursing homes), which may lack generalizability. Large-scale studies that focus on aging and personal networks, or that have a social network component (i.e., the American Social Fabric Study (Smith et al. 2015), the General Social Survey (Burt, 1984), and the National Social Life, Health, and Aging Project (Cornwell et al. 2014)) have only collected limited, incomplete socio-centric information. The under-representation of large-scale research on age differences in whole network structure therefore represents a gap in the current state of knowledge in this arena. It is important to note that self-reports of any aspect of social networks are cognitively derived and do not necessarily represent objective measurements of real networks (Koehly \& Marcum, 2018). However, mapping how individuals perceive the composition and structure of their social world, and the potential age differences in these perceptions, can provide important clues into how views of social relationships are regulated (Krackhardt, 1987).

In this paper, we make substantial headway in filling this void by evaluating the extent to which there are age differences in how individuals perceive their social worlds to be structured. Our data are drawn from a large sample of ego-centered cognitive networks $(n=1,824)$ consisting of close personal ties of family members and important others reported on by a sample of respondents representative of the U.S. adult population with respect to age, gender and race. We examine age differences in how individuals perceive their relationships within close personal networks (i.e., ego-alter or entirely ego-centered) relative to how they see the connections among their network members (i.e., alter-alter or socio-centric).

\section{Research Design \& Methods}

Our data were drawn from an online network survey fielded to a consumer panel of respondents living within the US and matched to be representative of the US adult population on age, sex, and race (provided by QSample ${ }^{\mathrm{TM}}$ ). The inclusion criteria were being aged 18 or older, English speaking, US residing, and willing to provide information on oneself and at least one network member. A total of 4,467 individuals from the consumer panel were invited to participate. After some attrition due to eligibility criteria screening and incomplete survey responses, we achieved an effective response rate of about $53 \%$. Details of the study design are available in a preprint of the descriptive summary (Marcum et al., 2017). Figure 1 explains the flow of participants from recruitment to completion.

\section{[[FIGURE 1 ABOUT HERE]]}

Respondents (egos) reported background information on themselves and were then asked to list network members (alters) on two enumerators designed to elicit only close personal social networks:

Immediate family: We'd like to learn about people that are important to you. First, please list all members of your family of origin (parents and siblings) and your nuclear family (spouse/partner and children). We'll ask about other important people later. 
Other important people: Now we'd like you to think about other people that are important to you that are not members of your family of origin or nuclear family. Please list other people that are important to you, such as extended family members (your grandmother, grandchildren, cousins, etc.), family through marriage (mother-in-law, brother-in-law), friends, and coworkers.

Age, living/deceased status, kinship relationship to the respondent, and gender of each network member was also recorded. Respondents then reported information about their social ties with each living network member and their perceptions of the social ties between each pair of living network members. This network information included perceptions of: acquaintanceship, cohesion, conflict, advice sharing, health discussion, geographic proximity, and social support (sharing feelings and comfort). In this study, we examine age differences in perceived acquaintanceship in both ego-alter (as measured by their network size) and alter-alter (as measured by the perceptions ego has of their degrees) ties. These two cognitive perceptions of ego's and alters' networks are illustrated in the cartoon of Figure 2.

\section{[[FIGURE 2 ABOUT HERE]]}

We use a combination of descriptive and multivariate network analysis to examine patterns in age differences with these data. Specifically, we first calculate and examine mixing-matrices (Newman, 2003; Marcum \& Koehly, 2015) to examine patterns of age-based social contact for ego-alter and alter-alter ties. Next, we test for age differences in ego network size and alter degree using Poisson regression via generalized estimating equations, which models count-like dependent variables while accounting for clustering within networks (Hardin and Hilbe, 2002). Our dependent variable for ego is network size and our dependent variable for ego's perceptions of alters connections is alter degree. Network size is defined as the number of network members (alters) each respondent (ego) enumerated. Similarly, alter degree is calculated as the number of ties each network member is perceived to have within each ego's network (minus, of course, their ties to ego as this is a constant within networks). To account for overdispersion in both dependent variables, we estimate a free scale parameter for the rate function of the Poisson distribution. Model selection was done by Quaslikelihood Information Criteria, where smaller values are preferred. For the multivariate analysis, a few participants were removed due to missing covariates $(n=5)$, and thus the analytic sample size is 1,819 respondents reporting on their ties with 16,311 living alters.

For descriptive purposes, to compare ego and alter age-based data, we categorize reported ego age into roughly 5-year age-groups as that is the finest precision which we could accurately capture the ages of respondent's network members. Ego age was coded with 18-24 and 80+ (13 categories), and alter age was coded with $0-4$ and 100+ (21 categories), respective bottom and top codes due to sampling limitations. In our multivariate statistical analysis, however, we operationalize age as a centered continuous variable to facilitate estimation and interpretation. 
Our Poisson regression model for ego's network size controls for ego's density of alter-alter ties, gender, race/ethnicity, education, marital status, and US geographic region. Our model for alters's degree additionally controls for ego/alter gender, kinship status, and ego marital status.

\section{Results}

Table 1 reports descriptive statistics on the respondents by age-groups. Raw counts are reported with associated percents or standard deviations in parentheses. About $22 \%$ of the sample was aged 60 or older and only $1 \%$ was aged 80 or older. On average, most respondents were female across all age-groups, though males tended to be slightly over-represented in ages 50-64. Along the margins, average network size tended to increase slightly while density tended to decrease, along age-groups. Each level of educational attainment was well-represented across age-groups. Descriptives of current marital status are also unremarkable, with an increasing percentage of widows, a decreasing percentage of singles, and relatively constant number of married persons as age increases. We also report that there were a larger than expected percentage of individuals ages 65 and older who did not report, refused, or were missing on marital status. At younger ages, we observe a good representation across race and ethnicity categories in the sample, with about $70 \%$ non-Hispanic whites, about $15 \%$ nonHispanic blacks, about 16\% Hispanics, and about 10\% Asian and native Americans/Pacific Islanders. Older age-groups, however, are predominantly comprised of non-Hispanic whites. Finally, we report geographic variation of the sample that is fairly consistent across age-groups (per postal zip-code regions).

Age-based mixing-matrices, which exhibit the relative volume of ties observed between members of each age-group with members of all other age-groups, provide greater detail on generational patterning of social ties. Figure 3 illustrates such age-based mixing for both ego's ties to their network members (left panel) and ego's perceptions of the ties between their alters (right panel). The intensity of the color in each cell is proportional to the relative tie volume flowing between members of the row- and column- age groups (darker=greater volume). Agebased homophilous ties are indexed along the (approximate) diagonal and heterophilous ties are indexed "off-diagonal." As expected, there is evidence of a strong pattern of age-homophily in both ego reports of their own ties and their reports of the perceptions of ties among their alters. Moreover, off-diagonal bands that parallel the age-homophily trend along the diagonal are evident in both mixing-matrices. The approximately 25 year age-difference (in both directions) from the age-homophily diagonal is characteristic of intergenerational age-mixing. Inspection of the pearson residuals from a log-linear model of both of these matrices suggests that these bands are significantly non-random $\left(X^{\wedge} 2=5876.4\right.$ on 240 d.f. $p<0.001 ; 14072$ on 400 d.f., $p<0.001$ ). Notably, the exception to these results are among the oldest ego age-group, which exhibits lower age-homophily and greater age-heterophily across the alter age spectrum.

[[FIGURE 3 ABOUT HERE]]

[[TABLE 1 ABOUT HERE]] 
The main age-difference results of the Poisson regression analyses are presented in Table 2 (full model results are available in Appendix A). Results for egos are reported in the first set of columns and results for alters are reported in the second columns.For both dependent variables, Model 1 reports independent age effects without interaction terms present between ego and alter age and Model 2 reports conditional age effects with an interaction term. Contrary to previous research, we find a positive effect of ego age on close personal network size, net of controls in both Model 1 and Model 2. However, we also find a negative effect of the mean age of alters on ego network size. This suggests that the older the composition of one's network, the smaller it is net of other factors. The interaction term in Model 2 is not significant, suggesting that only the main age effects matter for predicting ego's network size. When considering perceived alters' degrees, we initially find a significant negative effect of alter age on the number of perceived ties and a non-significant positive effect of ego age in Model 1. However, the interaction term is significant and negative and the ego-age effect remains essentially zero in Model 2. That is, any effect of ego's own age on their perceptions of their alters' connections appears to be explained by the interaction between their own age and their alters' ages.

For comparative purposes, Figure 4 depicts the interaction from Model 2 for both dependent variables. The leftmost panel represents the positive effect of ego's own age on their network size in dark blue and negative effect of the average age of their alters on their own network size in light blue (first dependent variable). The rightmost panel represents the null effect of ego's age on their perceptions of their alter's degree in dark blue and the negative effect of alter's age on ego's perceptions of their degrees in light blue (second dependent variable).

\section{[[TABLE 2 ABOUT HERE]]}

\section{[[FIGURE 4 ABOUT HERE]]}

\section{Discussion and Implications}

In this paper, we investigated age differences in age composition of network members and differences between one's own relationships and perceived relationships between others based on the close personal networks of a US population-based sample. Overall, we found that the past finding of a negative relationship between age and network size may be more nuanced than previously theorized. Rather, contrary to the age as network insulator hypothesis, we found a positive association between ego age and network size. This result is consistent with other recent studies of networks and aging, including Cornwell et al. (2014) who report that network growth was more common than decline in a longitudinal panel. This may be indicative of how demographic changes have shaped contemporary social networks--no longer is aging associated with withdrawal into a socially insulated world. However, while individuals perceive themselves to be well-connected, they also perceive other older adults in their own network to have fewer network ties. This suggests that age as network insulator is a pervasive belief, likely a result of the social construction of age and older adulthood, rather than a true demographic trend. Moreover, we found evidence that this belief is equally pervasive among younger and 
older people. Net of ego's age, we observed a strong negative association between the alters' ages and ego's perceptions of their ties.

We also observe a substantial amount of heterogeneity in network age composition across all age-groups. Compared to middle aged participants, both young and older adults have relatively less diverse personal networks when it comes to the age-composition of their networks. A closer look suggests that such an observation is a byproduct of the age structure itself, whereby both young and older adults are more constrained by the availability of possible personal network members. This can be readily seen from the age-mixing results. We find strong evidence of age-homophily from both ego-alter and alter-alter perspectives. There is also a signal of ageheterophily across all age-groups, albeit more muted (especially for perceived ties among middle-aged alters). Taken together, evidence in these data suggests that such age-mixing is likely the result of intergenerational contact: tellingly, the oldest age-groups in our study are the most likely to engage in age-heterophilous social connections and exhibit the least amount of age-homophily. This is consistent with the perspective that while loss of network members among the oldest age groups is inevitable due to the force of mortality, older adults also compensate such loss by engaging in intergenerational relations (Cornwell \& Laumann 2018; Cornwell et al. 2008; Bengtson, 2001).

Our results also reveal how age operates as a symbolic construct within cognitive personal networks. Normative expectations about aging (and indeed likely ageism) may underlie why individuals perceive their older network members to have fewer ties. This reflects the critical role of cultural beliefs and knowledge in defining individuals' perceptions about aging and the decline of social connections. In spite of their own networks, the socially accepted norm of fewer ties and smaller networks may be used by individuals to construct schemas of their social world (Kilduff, Crossland, Tsa, \& Krackhardt, 2008). This interpretation was foreshadowed by Ward's (1984) theory on such symbolic representations of age and aging in personal networks. To paraphrase, he argued that age, conceived as a personal trait has little bearing on individual social lives, but age conceived as a symbolic representation of marginalization insulates older adults from social networks. Our results point to such disconnect: on the one hand, one's own age is not perceived to be socially insulating, and on the other hand, normative expectations of the marginalization of age, in Ward's words, induces individuals to believe their older network members have fewer ties.

We note several limitations of the study. First, this is a cross-sectional design and as a result, the age effect we found is potentially a combination of a true time effect, a cohort effect, and an age-grading. We speculate that, because of the stark contrast of the age patterns in self and perceived personal networks, at least portions of this age effect can be attributed to the symbolic meaning of age, which shapes individual beliefs about older adults' social networks. Future studies should further disentangle the issue with longitudinal data, specifically by adding socio-centric measurement to a panel design. Second, while nationally representative in terms of age and race/ethnicity, our sample comes from a consumer panel where the participants have higher levels of education and are more familiar with taking online surveys compared to the population. Our results therefore have limited generalizability, especially in socially 
disadvantaged subpopulations. Future work should extend this line of inquiry across social strata, focusing on recruiting participants with lower socioeconomic status. Such work would be essential to our scientific understanding of changing heterogeneity in network structure with age and how this process is socially regulated. Finally, we have chosen to focus on perceptions of acquaintanceship in close personal networks. While acquaintanceship is a precondition for many other types of relationships, it is not a particularly strong tie. The ego-centered cognitive aspects of these data may elicit unrealistic perceptions of the networks. However, we argue that these cognitive networks represent mental maps of individual social worlds which allowed us to learn how the symbolic construct of age is embodied in these cognitive maps. However, we do see a multiple-informant cognitive social structure (Marcum et al., 2017) design as a better approach in future research as such a design will elicit networks closer to reality while preserving individual cognitive insights.

These limitations notwithstanding, our study using contemporary, nationally representative data on cognitive personal networks across the adult life span, constitutes an important step forward in answering questions regarding the significance of age in shaping individuals' social networks. Our focus on cognitive networks consisting of alter-alter ties among a large U.S. sample is novel and sheds light on a previously obscure aspect of research on aging and social networks. These results challenge past findings that suggest aging uniformly insulates individuals from social contact; on the contrary, we find that there is massive heterogeneity in perceived network structure associated with age and explaining that heterogeneity should be the pursuit of future research.

\section{References}

Ajrouch, K. J., Antonucci, T. C., \& Webster, N. J. (2014). Volunteerism: Social network dynamics and education. Journals of Gerontology Series B: Psychological Sciences and Social Sciences, 71(2), 309-319. DOI: https://doi.org/10.1093/geronb/gbu166

Antonucci, T. C., \& Akiyama, H. (1987). Social networks in adult life and a preliminary examination of the convoy model. Journal of Gerontology, 42(5), 519-527. DOI: https://doi.org/10.1093/geronj/42.5.519

Ashida, Sato, and Catherine Heaney. 2008. Differential Associations of Social Support and Social Connectedness with Structural Features of Social Networks and the Health Status of Older Adults. Journal of Aging and Health, 20, 872-93. DOI:

https://doi.org/10.1177/0898264308324626

Baltes, P. B., \& Baltes, M. M. (1990). Psychological perspectives on successful aging: The model of selective optimization with compensation. In P.B Baltes \& M.M. Baltes (eds), Successful aging: Perspectives from the behavioral sciences. 1-34. DOI: https://doi.org/10.1017/cbo9780511665684.003

Bengtson, V. L. (2001). Beyond the nuclear family: The increasing importance of multigenerational bonds. Journal of Marriage and Family, 63(1), 1-16. DOI:

https://doi.org/10.1111/j.1741-3737.2001.00001.x 
Burt, R. S. (1984). Network items and the General Social Survey. Social Networks, 6(4), 293339. DOI: https://doi.org/10.1016/0378-8733(84)90007-8

Carstensen, Laura L. 1991. Socioemotional Selectivity Theory: Social Activity in life-span context. In Annual Review of Gerontology and Geriatrics, K Warner Schaie and M P Lawton (eds), Vol 11, pp. 195-217. New York: Springer.

Cornwell, B., \& Laumann, E. O. (2018). Structure by Death: Social Network Replenishment in the Wake of Confidant Loss. In Social Networks and the Life Course: Integrating the Development of Human Lives and Social Relational Networks. Duane F. Alwin, Diane H. Felmlee, Derek A. Kreager (eds). pp. 343-365. Springer: Cham. DOI: https://doi.org/10.1007/9783-319-71544-5_16

Cornwell, B., Laumann, E.O., \& Schumm, L.P. 2008. "The Social Connectedness of Older Adults: A National Profile." American Sociological Review, 73, 185-203. DOI:

https://doi.org/10.1177/000312240807300201

Cornwell, Benjamin, L. Philip Schumm, Edward O. Laumann, Juyeon Kim, and Young-Jin Kim. 2014. Assessment of social network change in a National Longitudinal Survey. Journals of Gerontology Series B: Psychological Sciences and Social Sciences, 69, S75-S82. DOI: https://doi.org/10.1093/geronb/gbu037

Crimmins, E. M., \& Beltrán-Sánchez, H. (2011). Mortality and morbidity trends: Is there compression of morbidity? The Journals of Gerontology: Series B, 66(1), 75-86. DOI: https://doi.org/10.1093/geronb/gbq088

Cummings, E., \& Henry, W. E. (1961). Growing old. New York: Basic.

Feld, S. L., Suitor, J. J., \& Hoegh, J. G. (2007). Describing changes in personal networks over time. Field methods, 19(2), 218-236. DOI: https://doi.org/10.1177/1525822X06299134

Field, D., \& Minkler, M. (1988). Continuity and change in social support between young-old and old-old or very-old age. Journal of Gerontology, 43(4), P100-P106. DOI:

https://doi.org/10.1093/geronj/43.4.p100

Fries, J. F. (2002). Aging, natural death, and the compression of morbidity. Bulletin of the World Health Organization, 80(3), 245-250. DOI: https://doi.org/10.1056/nejm198403083101019

Hardin, J. W., \& Hilbe, J. M. (2002). Generalized Estimating Equations. Chapman and Hall/CRC: London

Kilduff, M., Crossland, C., Tsai, W., \& Krackhardt, D. (2008). Organizational network perceptions versus reality: A small world after all? Organizational Behavior and Human Decision Processes, 107(1), 15-28. DOI: https://doi.org/10.1016/i.obhdp.2007.12.003 
Koehly, L.M. \& Pattison, P. (2005). Random graph models for social networks: Multiple relations or multiple raters. In Peter J. Carrington, John Scott, and Stanley Wasserman (Eds), Models and Methods for Social Network Analysis, Cambridge University Press: Cambridge. 162-191. DOI: https://doi.org/10.1017/cbo9780511811395.009

Kohli, M. (2000). Age integration through interest mediation: Political parties and unions. The Gerontologist, 40(3), 279-282. DOI: https://doi.org/10.1093/geront/40.3.279

Kohli, M., Hank, K., \& Künemund, H. (2009). The social connectedness of older Europeans: patterns, dynamics and contexts. Journal of European Social Policy, 19(4), 327-340. DOI: https://doi.org/10.1177/1350506809341514

Krackhardt, D. (1987). Cognitive social structures. Social Networks, 9(2), 109-134. DOI: https://doi.org/10.1016/0378-8733(87)90009-8

Kumbasar, E., Romney, A. K., \& Batchelder, W. H. (1994). Systematic biases in social perception. American Journal of Sociology, 100(2), 477-505. DOI: https://doi.org/10.1086/230544

Lang, F. R., \& Baltes, M. M. (1997). Being with people and being alone in late life: Costs and benefits for everyday functioning. International Journal of Behavioral Development, 21(4), 729746. DOI: https://doi.org/10.1080/016502597384640

Lang, F. R., Rieckmann, N., \& Baltes, M. M. (2002). Adapting to aging losses: Do resources facilitate strategies of selection, compensation, and optimization in everyday functioning? The Journals of Gerontology Series B: Psychological Sciences and Social Sciences, 57(6), P501P509. DOI: https://doi.org/10.1093/geronb/57.6.p501

Marcum, C. S. (2013). Age differences in daily social activities. Research on Aging, 35(5), 612640. DOI: https://doi.org/10.7249/wr904

Marcum, C. S., \& Koehly, L. M. (2015). Inter-generational contact from a network perspective. Advances in Life Course Research, 24, 10-20. DOI: https://doi.org/10.1016/j.alcr.2015.04.001

Marcum, C. S., Lienert, J., Goldring, M., Lin, J., Miggins, A., Moss, M., ... \& Koehly, L. (2017). Ego-centered cognitive social structures of close personal networks in the United States. DOI: 10.31235/osf.io/pg3yx

Margolis, R., \& Verdery, A. M. (2017). Older adults without close kin in the United States. The Journals of Gerontology: Series B, 72(4), 688-693. DOI: https://doi.org/10.1093/geronb/gbx068

McPherson, M., Smith-Lovin, L., \& Cook, J. M. (2001). Birds of a feather: Homophily in social networks. Annual Review of Sociology, 27(1), 415-444. DOI:

https://doi.org/10.1146/annurev.soc.27.1.415 
Mok, D., \& Wellman, B. (2007). Did distance matter before the Internet?: Interpersonal contact and support in the 1970s. Social Networks, 29(3), 430-461. DOI:

https://doi.org/10.1016/j.socnet.2007.01.009

Newman, M. E. (2003). Mixing patterns in networks. Physical Review E, 67(2), 026126. DOI: https://doi.org/10.1103/physreve.67.026126

Putney, N. M., \& Bengtson, V. L. (2003). Intergenerational relations in changing times. In Handbook of the Life Course. Springer: Boston, MA. 149-164. DOI: https://doi.org/10.1007/978-0306-48247-2_7

Rook, K. S., \& Ituarte, P. H. (1999). Social control, social support, and companionship in older adults' family relationships and friendships. Personal Relationships, 6(2), 199-211. DOI:

https://doi.org/10.1111/j.1475-6811.1999.tb00187.x

Sherman, S. R., Ward, R. A., \& LaGory, M. (1985). Socialization and aging group consciousness: The effect of neighborhood age concentration. Journal of Gerontology, 40(1), 102-109. DOI: https://doi.org/10.1093/geronj/40.1.102

Silverstein, M., \& Giarrusso, R. (2010). Aging and family life: A decade review. Journal of Marriage and Family, 72(5), 1039-1058. DOI: https://doi.org/10.1111/j.1741-3737.2010.00749.x

Smith, E. J., Marcum, C. S., Boessen, A., Almquist, Z. W., Hipp, J. R., Nagle, N. N., \& Butts, C. T. (2015). The relationship of age to personal network size, relational multiplexity, and proximity to alters in the Western United States. Journals of Gerontology Series B: Psychological Sciences and Social Sciences, 70(1), 91-99. DOI: https://doi.org/10.1093/geronb/gbu142

Suitor, J. J., Wellman, B., \& Morgan, D. L. (1997). It's about time: How, why, and when networks change. Social networks, 19(1), 1-7. DOI: https://doi.org/10.1016/S0378-8733(96)00287-0

Van Tilburg, T. (1998). Losing and gaining in old age: Changes in personal network size and social support in a four-year longitudinal study. The Journals of Gerontology Series B:

Psychological Sciences and Social Sciences, 53(6), S313-S323. DOI:

https://doi.org/10.1093/geronb/53b.6.s313

Verdery, A. M., \& Margolis, R. (2017). Projections of white and black older adults without living kin in the United States, 2015 to 2060. Proceedings of the National Academy of Sciences, 201710341. DOI: https://doi.org/10.1073/pnas.1710341114

Ward, R. A. (1984). The marginality and salience of being old: When is age relevant?. The Gerontologist, 24(3), 227-232. DOI: https://doi.org/10.1093/geront/24.3.227

Wasserman, S., \& Faust, K. (1994). Social network analysis: Methods and applications (Vol. 8). Cambridge University Press: Cambridge 
White, L. (2001). Sibling relationships over the life course: A panel analysis. Journal of Marriage and Family, 63(2), 555-568. DOI: https://doi.org/10.1111/j.1741-3737.2001.00555.x

\section{Tables and/or Figures}


Table 1. Descriptive Statistics of the Sample by Age Group

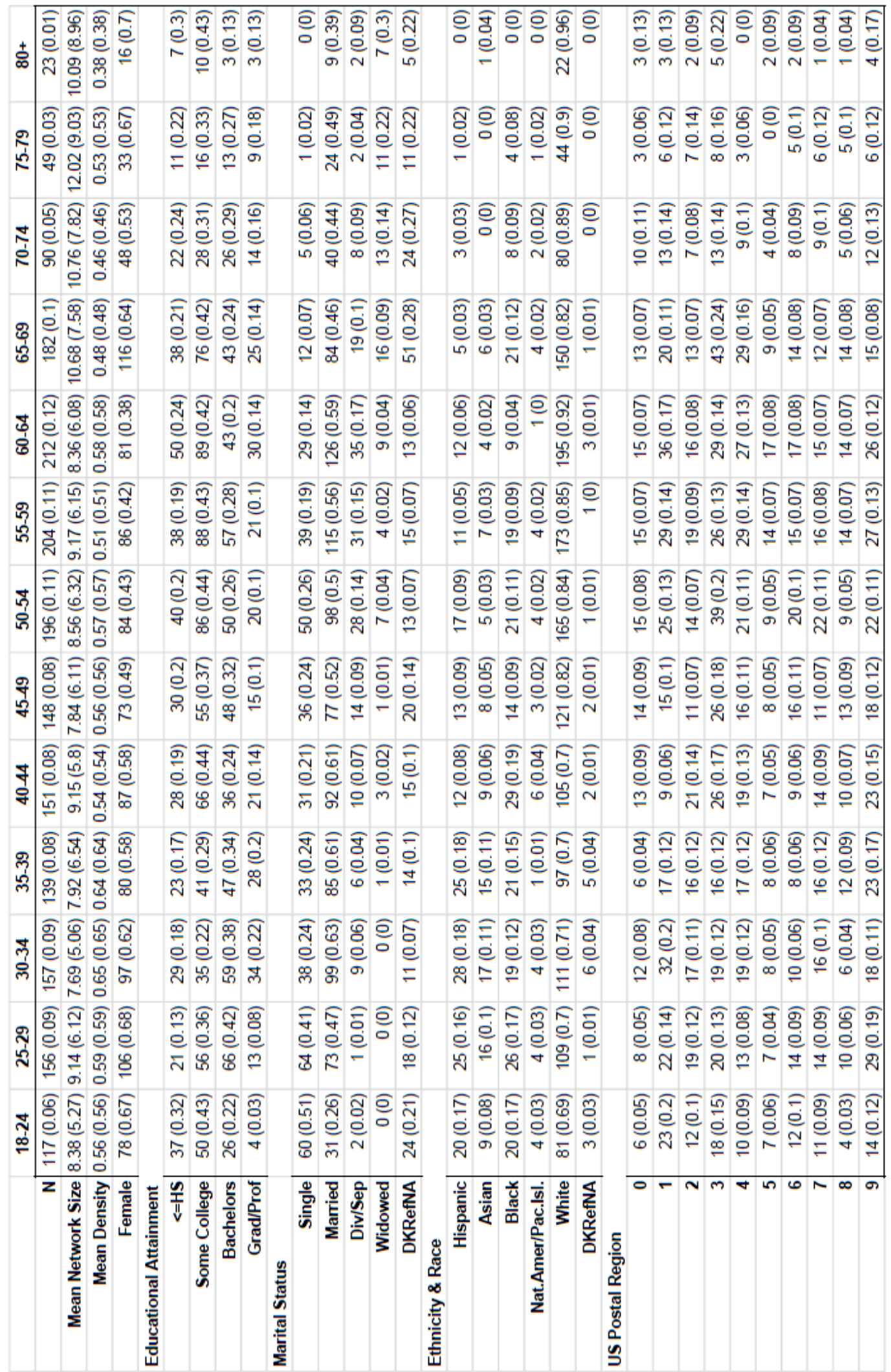




\begin{tabular}{|c|c|c|c|c|c|c|c|c|}
\hline & \multicolumn{4}{|c|}{ Ego's Network Size } & \multicolumn{4}{|c|}{ Alters' Degrees } \\
\hline & \multicolumn{2}{|c|}{ Model 1} & \multicolumn{2}{|c|}{ Model 2} & \multicolumn{2}{|c|}{ Model 1} & \multicolumn{2}{|c|}{ Model 2} \\
\hline & \multirow{2}{*}{$\frac{\text { Coef. }}{0.033^{* * *}}$} & \multirow{2}{*}{\begin{tabular}{|c|} 
Robust Z \\
5.207
\end{tabular}} & $\begin{array}{ll}\text { Coef. } & \text { Robust Z } \\
\end{array}$ & Robust Z & \multirow{2}{*}{\begin{tabular}{l|l} 
Coef. & $\mathrm{R}$ \\
0.003
\end{tabular}} & $\begin{array}{c}\text { Robust } \\
\mathrm{Z}\end{array}$ & \multirow{2}{*}{\begin{tabular}{l|l} 
Coef. & F \\
-0.011
\end{tabular}} & $\begin{array}{c}\text { Robust } \\
\text { Z }\end{array}$ \\
\hline Ego Age & & & $0.031^{* \star *}$ & 4.892 & & 0.227 & & -0.73 \\
\hline Mean Alter Age & $-0.029^{* * *}$ & -4.066 & $-0.028^{* * *}$ & -3.823 & & & & \\
\hline $\begin{array}{l}\text { Ego Age X Mean } \\
\text { Alter Age }\end{array}$ & & & -0.003 & -1.464 & & & & \\
\hline Alter Age & & & & & $-0.017^{* * *}$ & $\begin{array}{c}- \\
7.719\end{array}$ & $-0.017^{* * *}$ & * -7.579 \\
\hline Ego Age X Alter Age & & & & & & & $-0.002^{* \star *}$ & -3.46 \\
\hline Intercept & $2.557^{* * *}$ & 25.624 & $2.580^{* * *}$ & 25.571 & $1.641^{\star * *}$ & 8.23 & $1.632^{* * *}$ & 8.574 \\
\hline \multicolumn{9}{|l|}{ Model Details } \\
\hline Correlation Structure & \multicolumn{4}{|c|}{ Identity } & \multicolumn{4}{|c|}{ Exchangeable } \\
\hline Scale Parameter & 3.522 & & 3.52 & & 5.011 & & 4.973 & \\
\hline Full Model QIC & -40163.23 & & -40170.25 & & -90241.46 & & -90688.25 & \\
\hline Null Model QIC & \multicolumn{4}{|c|}{-38920.92} & \multicolumn{4}{|c|}{-84808.98} \\
\hline No. Observations & \multicolumn{4}{|c|}{1819} & \multicolumn{4}{|c|}{16311} \\
\hline \multirow{2}{*}{\multicolumn{9}{|c|}{$\begin{array}{l}\text { Notes: Ego's network size models control for ego's density of alter-alter ties, gender, race/ethnicity, } \\
\text { education, marital status, and region. Alters's degree models control for ego/alter gender, kin status, } \\
\text { and ego marital status. }\end{array}$}} \\
\hline & & & & & & & & \\
\hline \multicolumn{3}{|c|}{ QIC = Quasiliklihood Information Criteria } & & & & & & \\
\hline${ }^{* * *} p<0.001$ & & & & & & & & \\
\hline
\end{tabular}




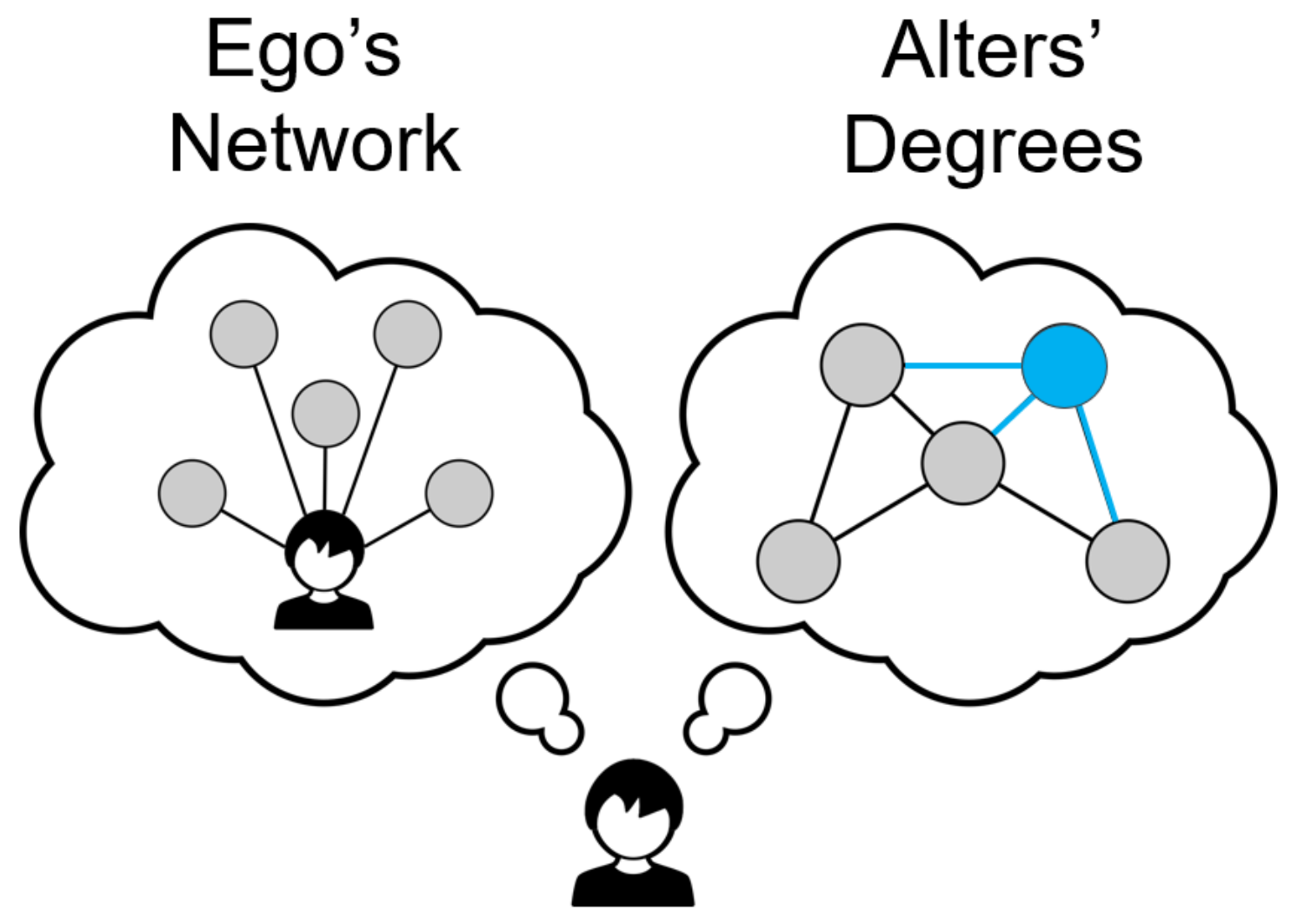

Figure 2. Cartoon illustrating the difference between ego's perceptions of his/her own ties and ego's perceptions of the ties between his/her network members (alters). In the left thought cloud ego's network size is equal to ego's network degree (i.e., the number of ties between members and ego), which is 5 here. In the right thought cloud Ego's alters' may be perceived to have different degrees, such as the highlighted alter having three connections to 3 alters who have, clockwise, 2, 4, and 3 connections. 


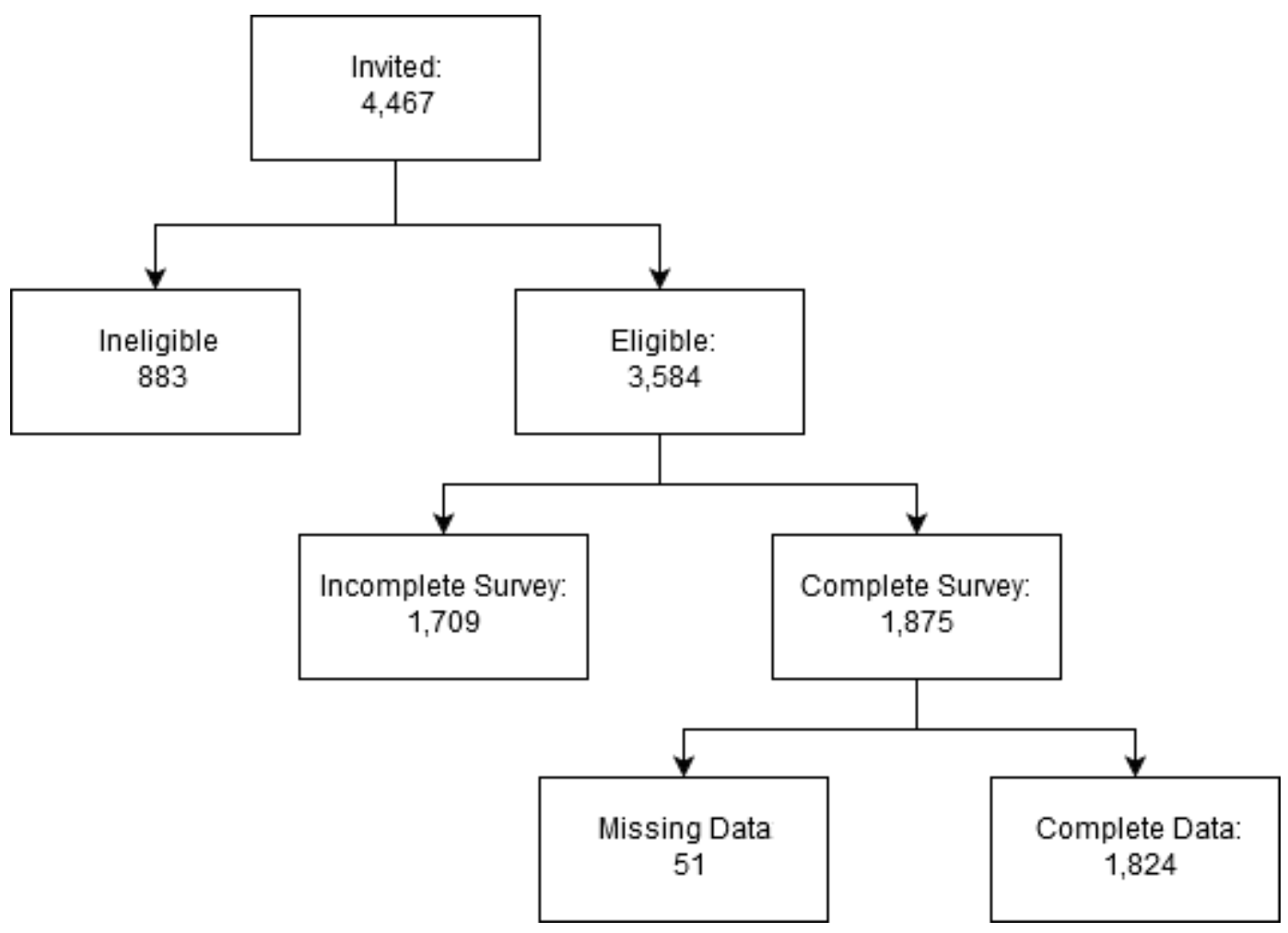

Figure 1. Structure of participant filtering of qSample consumer panel sample used in this study. The final sample size was 1,824 for the study. The sample size used in the multivariate GEE analysis was 1,819 as a five participants were missing covariate observations and were dropped. 


\section{Ego-Alter Mixing}

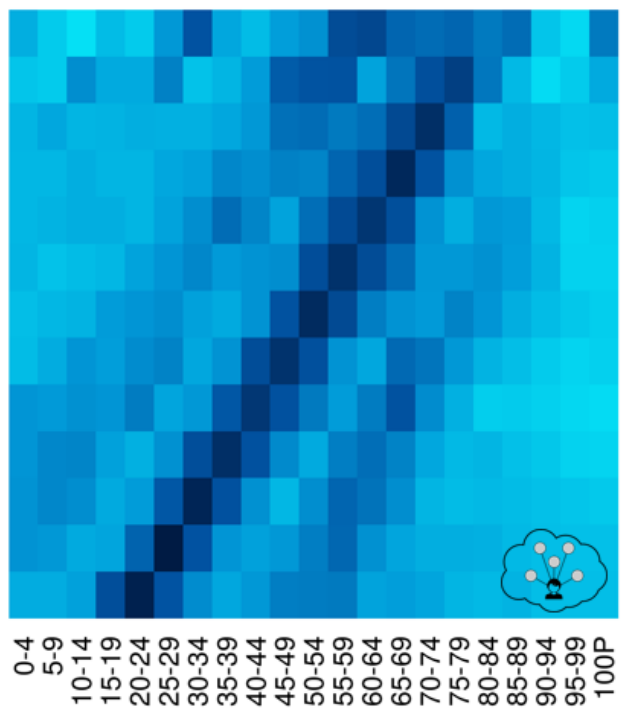

Alter Age

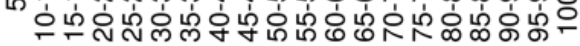

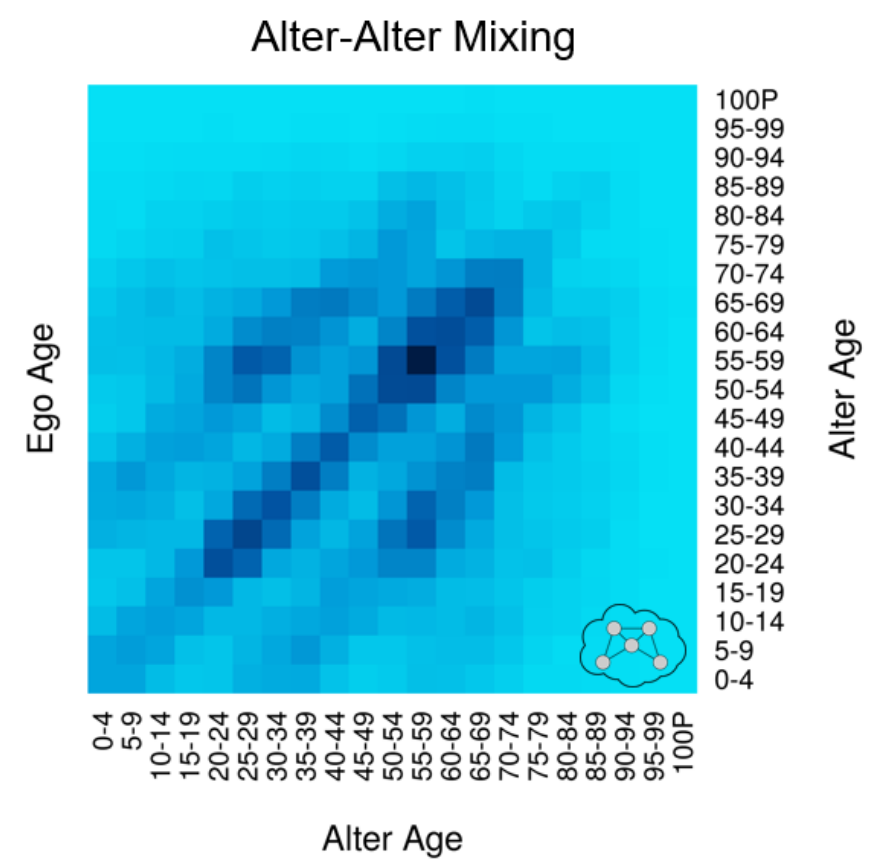

$80+$

75-79

70-74

65-69

60-64

55-59

50-54

45-49

40-44

35-39

30-34

25-29

18-24

Alter Age

Figure 3. Marginal age-based mixing matrices for ego-alter and alter-alter ties. 

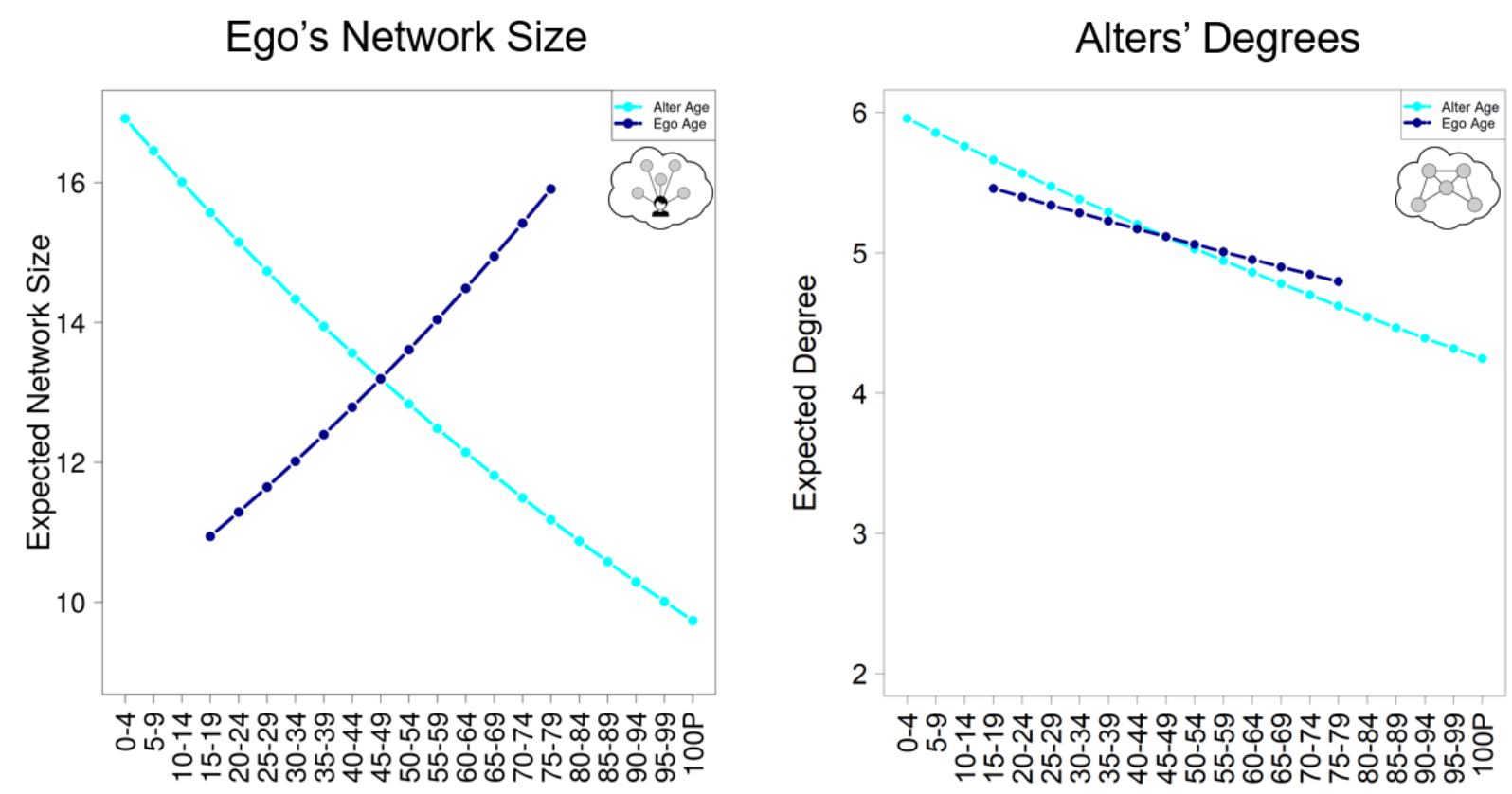

Figure 4. Ego and alter age marginal effects from the multivariate Poisson regression models reported in Table 2 (Models 2). 